\title{
Short communication: Enhanced clinical mastitis resistance in Holsteins with a FEZL p.Gly105(12_13) polymorphism
}

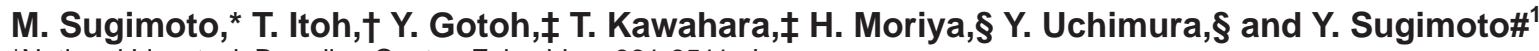 \\ *National Livestock Breeding Center, Fukushima 961-8511, Japan \\ †Maebashi Institute of Animal Science, Gunma 371-0121, Japan \\ łHolstein Cattle Association of Japan, Hokkaido Branch, Hokkaido 001-8555, Japan \\ §Tokachi NOSAI, Hokkaido 080-2331, Japan \\ \#Shirakawa Institute of Animal Genetics, Fukushima 961-8061, Japan
}

\section{ABSTRACT}

Mastitis is a common infectious disease of the mammary gland and a major problem in the dairy industry. We previously reported that forebrain embryonic zinc finger-like (FEZL) encoding a stretch of 12 glycines (p.Gly105[12]) instead of 13 glycines (p.Gly105[13]) is associated with a lower somatic cell score (SCS) in a family derived from Walkway Chief Mark. Here we report that the p.Gly105[12] allele is associated with a significantly decreased incidence of clinical mastitis in a large Holstein population. We genotyped the FEZL polymorphism in 918 randomly collected Holstein sires, and investigated the effect of the polymorphism on the estimated breeding value (EBV) for SCS and milk, fat, solids-not-fat, and protein yield, and on the number of cattle with clinical mastitis among daughters derived from these sires. The average EBV for SCS among sires carrying the heterozygous p.Gly105[12] was significantly lower than that among sires carrying the homozygous p.Gly105[13], whereas we found no unfavorable effects of this polymorphism on EBV for milk, fat, solids-not-fat, and protein yield. The proportion of cows with clinical mastitis derived from sires carrying heterozygous p.Gly105[12] was significantly lower than that of daughters derived from sires carrying the homozygous p.Gly105[13]. Thus, selection of sires carrying p.Gly105[12] could be beneficial in the dairy industry by reducing the incidence of mastitis.

Key words: cattle, mastitis, forebrain embryonic zinc finger-like, somatic cell score

\section{Short Communication}

Mastitis is an inflammation of the mammary gland caused by bacteria such as Escherichia coli that generates large losses in the dairy industry due to reductions

Received April 21, 2010.

Accepted December 14, 2010.

${ }^{1}$ Corresponding author: kazusugi@siag.or.jp in milk quality and quantity and increased health costs. Recently, linkage analysis of granddaughters derived from Walkway Chief Mark with high and low SCS during their first lactation period revealed that high SCS cows have a forebrain embryonic zinc finger-like (FEZL) protein with a longer glycine stretch; that is, 13 glycines (p.Gly105[13]) instead of 12 (p.Gly105[12]; Sugimoto et al., 2006). The FEZL protein is a transcription factor containing $\mathrm{C} 2 \mathrm{H} 2$-type zinc-finger domains and a glycine stretch (Matsuo-Takasaki et al., 2000). Treatment of bovine mammary epithelial cells with LPS induces FEZL expression followed by enhanced production of tumor necrosis factor- $\alpha$ and IL- 8 through semaphorin 5A expression (Sugimoto et al., 2006). Because p.Gly105[12] promotes higher semaphorin 5A expression than p.Gly105[13], the high SCS might be due to an impaired immune response of cows carrying p.Gly105[13].

The FEZL gene was mapped as influencing SCS in a large family derived from a specific sire, Walkway Chief Mark (Sugimoto et al., 2006); a strong genetic correlation exists between SCS and mastitis (Young et al., 1960; Emanuelson et al., 1988). The effects of the FEZL mutation on SCS and the incidence of mastitis, however, must be confirmed among randomly collected samples before genetic selection based on this gene can be implemented in the dairy industry. The aim of this study was to determine the effect of p.Gly105[12] on resistance to mastitis.

For genotyping of the FEZL p.Gly105(12_13) mutation, 918 DNA samples were prepared from semen according to standard protocols, and the DNA concentration was adjusted to $20 \mathrm{ng} / \mu \mathrm{L}$. The PCR reaction was performed in a volume of $15 \mu \mathrm{L}$ containing 20 ng of genomic DNA, $1.67 \mathrm{mM} \mathrm{MgCl}_{2}, 6.25 \mathrm{pmol}$ of each primer [forward: 5'(FAM)-ACTCTGAGCTCTGGAAAAGCAG-3'; reverse: 5'-CACACGCCACAAGTTGGTTT- $3^{\prime}$ ], $0.2 \mathrm{~m} M$ deoxynucleotides, and $0.375 \mathrm{U}$ of Taq DNA polymerase (ABgene, Epsom, UK). The thermal cycling conditions were 1 cycle $\left(94^{\circ} \mathrm{C}\right.$ for 3 min), 35 cycles $\left(94^{\circ} \mathrm{C}\right.$ for $1 \mathrm{~min}, 60^{\circ} \mathrm{C}$ for $1 \mathrm{~min}, 72^{\circ} \mathrm{C}$ 
Table 1. The average \pm SEM EBV for SCS, milk, fat, SNF, and protein yield of sires with heterozygous p.Gly105[12] compared with sires with homozygous p.Gly105[13] for the FEZL p.Gly105(12_13) mutation

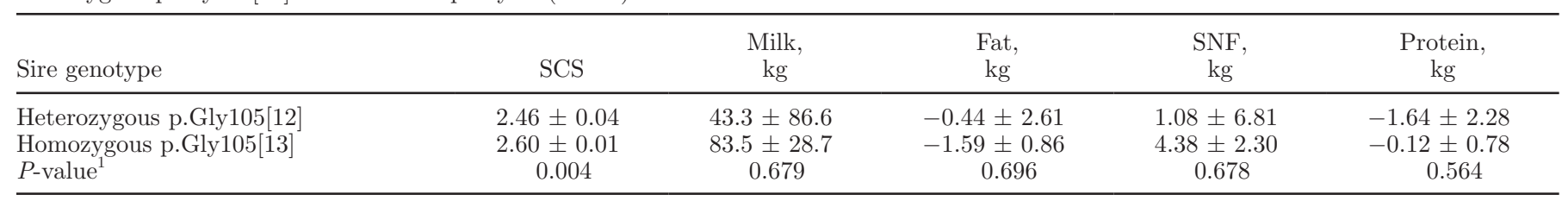

${ }^{1}$ Calculated by Student's $t$-test.

for $1 \mathrm{~min})$, and 1 cycle $\left(72^{\circ} \mathrm{C}\right.$ for $\left.10 \mathrm{~min}\right)$. Following $\mathrm{PCR}$, alleles were resolved using an ABI 3700 sequencer (Applied Biosystems, Foster City, CA) and genotype data were captured using GeneMapper 4.0 (Applied Biosystems).

Genotyping of FEZL in 918 sires revealed that 97 sires had a heterozygous p.Gly105[12] genotype and 821 sires had a homozygous p.Gly105[13] genotype. The National Livestock Breeding Center (Fukushima, Japan) evaluated the EBV for SCS of 693 sires having more than 15 daughters among these 918 sires using a mixed model including a fixed regression:

$$
y=H D+A+a t+b \times \exp (-0.05 t)+u+p e+e,
$$

where $y=$ SCS of first calving, $H D=$ fixed effects of herd-test day, $A=$ fixed effects of calving age groups, $t$ $=$ days in milk, $a$ and $b=$ coefficients of Wilmink's curves, $u=$ random effects of additive genetics (EBV) and $u \sim N\left(0, \mathbf{A} \sigma_{u}^{2}\right), \quad p e=$ random effects of permanent environment, $e=$ random residuals, and $e \sim N\left(0, \mathbf{A} \sigma_{e}^{2}\right)$, where $\mathbf{A}$ is the numerator relationship matrix among animals. Heritability for SCS was 0.082. The average EBV for SCS of the heterozygous p.Gly105[12] sires (n $=59$ ) was $2.47 \pm 0.04$, and the average EBV for SCS of the homozygous p.Gly105[13] sires $(\mathrm{n}=634)$ was $2.60 \pm 0.01$. Student's $t$-test revealed a difference between these 2 groups (Table 1). These findings confirmed that the p.Gly105[12] allele decreases SCS, not only in the Walkway Chief Mark family, but also in other families in Japan.

To estimate the effect of FEZL on the EBV for milk, fat, SNF, and protein yields, we compared the average EBV of heterozygous p.Gly105[12] sires $(\mathrm{n}=59)$ and homozygous p.Gly105[13] sires $(\mathrm{n}=634)$. The National Livestock Breeding Center calculated the EBV of each sire for milk, fat, SNF, and protein yield based on a single-trait animal model and a BLUP procedure. The relative EBV for milk, fat, SNF, and protein yields of homozygous p.Gly105[13] sires were not different from those of heterozygous p.Gly105[12] sires (Table 1).
These findings confirmed that the p.Gly105[12] allele does not have unfavorable effects on milk yield.

To determine the effect of FEZL on the incidence of mastitis, we compared the number of cows with mastitis among daughters derived from sires carrying heterozygous p.Gly105[12] or homozygous p.Gly105[13] for each year of age. The Veterinary Clinical Center, Tokachi NOSAI (Hokkaido, Japan), recorded clinical mastitis in the Tokachi area of Hokkaido from 2003 to 2007. Cows diagnosed with mastitis and treated at least once per lactation by veterinarians were considered affected. The Holstein Cattle Association of Japan, Hokkaido Branch, sorted the cows according to their sires and age. They collected 132,210 mastitis records in 491,725 lactation periods from 228,945 cows during these $5 \mathrm{yr}$ in this area. A total of 41,431 records in 162,655 lactation periods were from daughters of the 918 genotyped sires.

In daughters younger than 3 yr old, 2,136 (18.9\%) among 11,283 daughters derived from sires carrying heterozygous p.Gly105[12] were affected, whereas 12,691 (20.1\%) among 63,165 daughters derived from sires carrying homozygous p.Gly105[13] were affected (Table 2). Fisher's exact test (Agresti, 1992) indicated a difference $(P=0.004)$ between these 2 groups. Consistent with several reports that the incidence of mastitis in cows increases with age (Braund and Schultz, 1963; Batra et al., 1977; Gonyon et al., 1982), the percentage of cows affected in both heterozygous p.Gly105[12] and homozygous p.Gly105[13] daughters increased with age. At almost every age, however, the proportion of affected heterozygous p.Gly105[12] daughters was significantly lower than that of affected homozygous p.Gly105[13] daughters (Table 2). These findings confirmed that FEZL affects the incidence of mastitis as well as SCS.

Escherichia coli is very common in the dairy cow environment, and the severity of mastitis caused by this bacterium is determined mainly by cow factors rather than by E. coli pathogenicity (Burvenich et al., 2003). Lipopolysaccharides from E. coli induced FEZL expression in bovine mammary epithelial cells (Sugimoto et al., 2006). To examine whether the FEZL genotype affects the incidence of $E$. coli-caused mastitis, we com- 
Table 2. The number of cows (\% in parentheses) affected with mastitis in daughters from sires with heterozygous p.Gly105[12] compared with daughters of sires with homozygous p.Gly105[13] grouped by age

\begin{tabular}{|c|c|c|c|c|c|c|c|c|c|c|}
\hline \multirow[b]{3}{*}{ Sire genotype } & \multicolumn{10}{|c|}{ Age, yr } \\
\hline & \multicolumn{2}{|c|}{$<3$} & \multicolumn{2}{|c|}{ Between 3 and 4 yr } & \multicolumn{2}{|c|}{ Between 4 and 5 yr } & \multicolumn{2}{|c|}{ Between 5 and 6 yr } & \multicolumn{2}{|c|}{ More than 6 yr } \\
\hline & Affected & Unaffected & Affected & Unaffected & Affected & Unaffected & Affected & Unaffected & Affected & Unaffected \\
\hline Heterozygous p.Gly105[12] & $\begin{array}{l}2,136 \\
(18.9)\end{array}$ & $\begin{array}{l}9,147 \\
(81.1)\end{array}$ & $\begin{array}{l}1,619 \\
(26.1)\end{array}$ & $\begin{array}{l}4,594 \\
(73.9)\end{array}$ & $\begin{array}{l}1,184 \\
\quad(28.8)\end{array}$ & $\begin{array}{l}2,925 \\
\quad(71.2)\end{array}$ & $\begin{array}{l}662 \\
(32.4)\end{array}$ & $\begin{array}{l}1,384 \\
(67.6)\end{array}$ & $\begin{array}{l}211 \\
(26.4)\end{array}$ & $\begin{array}{l}588 \\
(73.6)\end{array}$ \\
\hline Homozygous p.Gly105[13] & $\begin{array}{c}12,691 \\
(20.1)\end{array}$ & $\begin{array}{l}50,474 \\
(79.9)\end{array}$ & $\begin{array}{c}11,065 \\
(27.9)\end{array}$ & $\begin{array}{r}28,588 \\
(72.1)\end{array}$ & $\begin{array}{c}6,872 \\
\quad(32.8)\end{array}$ & $\begin{array}{c}14,077 \\
(67.2)\end{array}$ & $\begin{array}{l}3,126 \\
(34.3)\end{array}$ & $\begin{array}{l}5,982 \\
(65.7)\end{array}$ & $\begin{array}{r}1,865 \\
(35)\end{array}$ & $\begin{array}{r}3,465 \\
(65)\end{array}$ \\
\hline$P$-value ${ }^{1}$ & \multicolumn{2}{|c|}{0.004} & \multicolumn{2}{|c|}{0.002} & \multicolumn{2}{|c|}{$5 \mathrm{E}-07$} & \multicolumn{2}{|c|}{0.09} & \multicolumn{2}{|c|}{$1 \mathrm{E}-06$} \\
\hline
\end{tabular}

${ }^{1}$ Calculated by Fisher's exact test.

Table 3. The number (\% in parentheses) of affected cows with Escherichia coli mastitis among daughters from sires with heterozygous p.Gly105[12] compared with daughters of sires with homozygous p.Gly105[13] grouped by age

\begin{tabular}{|c|c|c|c|c|c|c|c|c|c|c|}
\hline \multirow[b]{3}{*}{ Sire genotype } & \multicolumn{10}{|c|}{ Age, yr } \\
\hline & \multicolumn{2}{|c|}{$<3$} & \multicolumn{2}{|c|}{ Between 3 and 4 yr } & \multicolumn{2}{|c|}{ Between 4 and 5 yr } & \multicolumn{2}{|c|}{ Between 5 and 6 yr } & \multicolumn{2}{|c|}{ More than 6 yr } \\
\hline & Affected & Unaffected & Affected & Unaffected & Affected & Unaffected & Affected & Unaffected & Affected & Unaffected \\
\hline Heterozygous p.Gly105[12] & $\begin{array}{l}313 \\
(2.8)\end{array}$ & $\begin{array}{l}10,970 \\
(97.2)\end{array}$ & $\begin{array}{r}310 \\
(5)\end{array}$ & $\begin{array}{r}5,903 \\
(95)\end{array}$ & $\begin{array}{l}256 \\
(6.2)\end{array}$ & $\begin{array}{l}3,853 \\
(93.8)\end{array}$ & $\begin{array}{c}123 \\
(6)\end{array}$ & $\begin{array}{r}1,923 \\
(94)\end{array}$ & $\begin{array}{l}34 \\
(4.3)\end{array}$ & $\begin{array}{l}765 \\
(95.7)\end{array}$ \\
\hline Homozygous p.Gly105[13] & $\begin{array}{r}2,080 \\
(3.3)\end{array}$ & $\begin{array}{l}61,085 \\
(96.7)\end{array}$ & 2,234 & $\begin{array}{l}37,419 \\
(94.4)\end{array}$ & $\begin{array}{r}1,468 \\
(7)\end{array}$ & $\begin{array}{r}19,481 \\
(93)\end{array}$ & $\begin{array}{l}658 \\
(7.2)\end{array}$ & $\begin{array}{l}8,450 \\
(92.8)\end{array}$ & $\begin{array}{r}367 \\
(6.9)\end{array}$ & $\begin{array}{l}4,963 \\
(93.1)\end{array}$ \\
\hline$P$-value ${ }^{1}$ & \multicolumn{2}{|c|}{0.004} & \multicolumn{2}{|c|}{0.04} & \multicolumn{2}{|c|}{ (1) $0.07^{\text {(90) }}$} & \multicolumn{2}{|c|}{0.06} & \multicolumn{2}{|c|}{0.004} \\
\hline
\end{tabular}


Table 4. The average EBV (\%) for clinical mastitis of sires and of daughters from sires with heterozygous p.Gly105[12] or homozygous p.Gly105[13]

\begin{tabular}{|c|c|c|c|c|}
\hline \multirow[b]{2}{*}{ Sire genotype } & \multicolumn{2}{|c|}{ Sire based on daughter's phenotype } & \multicolumn{2}{|c|}{ Daughter } \\
\hline & Number & $\begin{array}{c}\text { EBV } \\
\pm \text { SEM }\end{array}$ & Number & $\begin{array}{c}\text { EBV } \\
\pm \text { SEM }\end{array}$ \\
\hline Heterozygous p.Gly105[12] & 74 & $23.3 \pm 0.57$ & 9,742 & $23.0 \pm 0.04$ \\
\hline Homozygous p.Gly105[13] & 654 & $24.6 \pm 0.25$ & 56,985 & $25.3 \pm 0.03$ \\
\hline$P$-value 1 & & 0.039 & & $<0.01$ \\
\hline
\end{tabular}

${ }^{1}$ Calculated by Student's $t$-test.

pared the number of cows affected by $E$. coli mastitis among daughters derived from sires carrying heterozygous p.Gly105[12] or homozygous p.Gly105[13] at each year of age. As shown in Table 3, at almost every age, the proportion of cows with E. coli-caused mastitis was significantly lower among heterozygous p.Gly105[12] daughters than among homozygous p.Gly105[13] daughters.

To more closely observe the effect of FEZL on the incidence of mastitis, we evaluated the EBV for mastitis using a threshold animal model:

$$
y=A+M+h y+u+p e+e,
$$

where $y=$ liabilities to mastitis recorded as 0 (normal) or 1 (clinical), $A$ = fixed effects of calving age group (24 groups classified in the range from 18 to 95 mo of age), $M=$ fixed effects of calving month (12 classes), $h y=$ random effects of herd-year of calving (11,992 subclasses), $u=$ random additive genetic effect (EBV) and $u \sim N\left(0, \mathbf{A} \sigma_{u}^{2}\right), p e=$ random effects of permanent environment, and $e=$ random residuals and $e \sim N(0,1)$, where $\mathbf{A}$ is the numerator relationship matrix among animals. The programs we used were THRGIBBSF90 to estimate variance components and CBLUP90THR to obtain animal EBV on the underlying scale (Misztal et al., 2002). The EBV of bulls and cows were converted into percentage EBV. Heritability for clinical mastitis was 0.06. Among sires having more than 5 daughters, the average percentage EBV for mastitis of the heterozygous p.Gly105[12] sires $(\mathrm{n}=75)$ was 23.3 $\pm 0.57 \%$. On the other hand, the average percentage EBV for mastitis of the homozygous p.Gly105[13] sires $(\mathrm{n}=654)$ was $24.6 \pm 0.25 \%$. Student's $t$-test revealed a difference between these 2 groups $(P=0.039$; Table 4$)$. The average percentage EBV for mastitis of daughters derived from sires carrying heterozygous p.Gly105[12] and homozygous p.Gly105[13] were $23.0 \pm 0.04 \%$ ( $\mathrm{n}=$ $9,742)$ and $25.3 \pm 0.03 \%(\mathrm{n}=56,985)$, respectively, which were significantly different $(P<0.01$; Table 4$)$. These findings confirmed that the p.Gly105[12] allele decreases clinical mastitis in terms of percentage EBV.
To confirm the robustness of our analysis, we also estimated the effect of the mutation in an animal model using daughter yield deviations of the sires (VanRaden and Wiggans, 1991). Among 1,429 sires related to Walkway Chief Mark, the average daughter yield deviations for mastitis of the heterozygous p.Gly105[12] sires, the homozygous p.Gly105[13] sires, and unknown sires were $-0.000357,0.007938$, and 0.000443 , respectively (Table $5)$. Duncan's multiple range test revealed a difference between the heterozygous p.Gly105[12] sires and the homozygous p.Gly105[13] sires $(P<0.05)$. This result indicated that the p.Gly105[12] genotype did have an effect to reduce mastitis incidence.

A survey of the FEZL p.Gly105(12_13) mutation in sires in Japan revealed that the p.Gly105[12] allele decreases both SCS and the incidence of mastitis. As suggested from cell-based studies (Sugimoto et al., 2006), the p.Gly105[12] allele might enhance immune responses, making the cows resistant to mastitis. Moreover, we demonstrated that the p.Gly105[12] allele is neutral in terms of milk, fat, SNF, and protein yields. Considering the high health costs associated with mastitis, it might be beneficial to select cows based on their FEZL genotype.

\section{ACKNOWLEDGMENTS}

The authors thank T. Asano and T. Yamashita (both of Holstein Cattle Association of Japan, Hokkaido Branch, Hokkaido, Japan) for assistance. This work was supported by the Japan Racing and Livestock Promotion Foundation (Tokyo, Japan).

Table 5. The average daughter yield deviation (DYD) for mastitis of the heterozygous p.Gly105[12] sires, the homozygous p.Gly105[13] sires, and unknown sires

\begin{tabular}{lcc}
\hline Sire genotype & Number & DYD \\
\hline Heterozygous p.Gly105[12] & 70 & $-0.000357^{\mathrm{a}}$ \\
Unknown & 996 & $0.000443^{\mathrm{a}}$ \\
Homozygous p.Gly105[13] & 363 & $0.007938^{\mathrm{b}}$ \\
\hline
\end{tabular}

${ }^{a, b}$ Values within a column followed by different superscript letters are different according to Duncan's multiple range test $(P<0.05)$. 


\section{REFERENCES}

Agresti, A. 1992. A survey of exact inference for contingency tables. Stat. Sci. 7:131-153.

Batra, T. R., B. J. Nonnechke, F. H. Newbould, and R. R. Hacker. 1977. Incidence of clinical mastitis in a herd of Holstein cattle. J. Dairy Sci. 60:1169-1172.

Braund, D. G., and L. H. Schultz. 1963. Physiological and environmental factors affecting the California Mastitis Test under field conditions. J. Dairy Sci. 46:197-203.

Burvenich, C., V. Van Merris, J. Mehrzad, A. Diez-Fraile, and L. Duchateau. 2003. Severity of E. coli mastitis is mainly determined by cow factors. Vet. Res. 34:521-564.

Emanuelson, U., B. Danell, and J. Philipsson. 1988. Genetic parameters for clinical mastitis, somatic cell counts, and milk production estimated by multiple-trait restricted maximum likelihood. J. Dairy Sci. 71:467-476.

Gonyon, D. S., D. O. Everson, and R. E. Christian. 1982. Heritability of mastitis score in Pacific Northwest dairy herds. J. Dairy Sci. 65:1269-1276.
Matsuo-Takasaki, M., J. H. Lim, M. J. Beanan, S. M. Sato, and T. D. Sargent. 2000. Cloning and expression of a novel zinc finger gene, $\mathrm{Fez}$, transcribed in the forebrain of Xenopus and mouse embryos. Mech. Dev. 93:201-204.

Misztal, I., S. Tsuruta, T. Strabel, B. Auvray, T. Druet, and D. H. Lee. 2002. BLUPF90 and related programs (BGF90). CD-ROM Commun. 28:07; Proc. 7th World Congr. Genet. Appl. Livest. Prod., Montpellier, France.

Sugimoto, M., A. Fujikawa, J. E. Womack, and Y. Sugimoto. 2006. Evidence that bovine forebrain embryonic zinc finger-like gene influences immune response associated with mastitis resistance. Proc. Natl. Acad. Sci. USA 103:6454-6459.

VanRaden, P. M., and G. R. Wiggans. 1991. Derivation, calculation, and use of national animal model information. J. Dairy Sci. 74:2737-2746.

Young, C. W., J. E. Legates, and J. G. Leece. 1960. Genetic and phenotypic relationships between clinical mastitis, laboratory criteria, and udder height. J. Dairy Sci. 43:54-62. 